\title{
Teens Surfing The Net: How Do They Learn To Protect Their Privacy?
}

Deborah M.Moscardelli, (E-mail: mosca2dm@cmich.edu), Central Michigan University Catherine Liston-Heyes, (E-mail: C.Liston-Heyes@rhul.as.uk), University of London

\begin{abstract}
This study invokes the consumer socialization process to investigate how teens develop knowledge of 'privacy concern' as it relates to protecting their privacy when using the Internet. The data in this study show a correlation between teens that are raised in homes where parents practice concept-oriented family communication and the development of privacy concern. The data also show a correlation between parental co-viewing of the Internet and the development of privacy concern. Finally, the date link peer communication with the development of privacy concern. Overall the date appear to show that discussion with parents and friends about Internet use is key to the development of adopting concern for protecting teens privacy when they use the Internet.
\end{abstract}

\section{Section 1: Introduction}

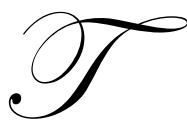

he purpose of investigating consumer socialization is to shed light on how children and adolescents learn to become consumers. Such studies are useful in devising policies and mechanisms that help educate and protect young consumers who are vulnerable and easily exploited in the marketplace. In order to educate and protect young consumers, researchers must identify the behaviors and cognitions (or consumer socialization outcomes) that both help and hinder competency in the marketplace.

In this study, we examine Internet privacy issues as they relate to the consumer socialization of adolescents. Since the Internet is now a major pillar of the marketplace it follows that protecting one's privacy should become one of the learning outcomes of the consumer socialization process given that consumer socialization outcomes are described a cognitions and behaviors that assist (or hinder) one's ability to function within society (Moschis 1985). We argue that teens must understand privacy issues in order to use the Internet safely. We empirically examine what are their perceptions and attitudes about privacy on the Internet. These findings are reconciled and interpreted within the consumer socialization framework.

The importance of the effects of the Internet on teen life can no longer be negated. For the adolescent segment, the Internet has increasingly become an important medium for investigation, as teens are perceived as both heavy and wide users of the Internet. Couple Internet connectivity with steady increases in the acquisition of 'pocket money' and the adolescent segment becomes a segment that is difficult for the commercial market to ignore. According to Teen Research Unlimited, American teenagers spent \$148 Billion in 1998 (up from $\$ 122$ Billion in 1997) (See (Gray 1999) and references therein). Other industry reports suggest teens not only have their own money to spend, but influence between $\$ 200$ and $\$ 500$ billion of household purchases (Colkin 2001). Adolescents not only have more money but also more time to spend it than previous generations given round-the-clock shopping opportunities offered by the Internet.

Unlike television, the Internet is a highly interactive medium whereby the consumer not only controls viewing content, but can knowingly and unknowingly transmit sensitive personal information. This characteristic implies that adolescents are 'in control' of viewing content although they may not have a thorough understanding of the consequences of the decisions they make Whilst viewing online content. Whilst the marketplace was once conceptualised in terms of physical space it has been transformed into a 'virtual' space in which buyers and sellers 
interact, and build relationships without ever meeting physically. The Internet enhances the physical marketplace allowing consumers to shop, browse, or seek information at their convenience twenty-four hours per day, seven days per week. Further, the Internet offers the perception of anonymity and security as the consumer can access the Internet from the privacy and security of their own home (Kehoe et al. 1997). The perception of anonymity and safety however may be a false one and is dependent on the consumer's knowledge of online data collection and privacy issues (Nowak and Phelps 1992). Therefore those consumers who have a thorough understanding of online data collection activities and privacy issues are better able to protect their interests in the online marketplace.

Although not previously investigated in a consumer socialization context, the issue of privacy has been ardently debated for the last several years particularly with regard to the child and adolescent segments. The Center for Media Education (CME), recently published a report that outlined attempts by Web sites to offer gifts to both children and teens in exchange for not only their personal information (e.g. name and mailing address) but information about household consumption and parents' income (Montgomery and Pasnik 1996). Moreover, Montgomery and Pasnik describe the use of prizes, games, surveys, seamless integration of advertising and content, and 'spokescharacters' in order to obtain personal information from young consumers on the Internet. As a result of media reports and subsequent public outcry over the study, the United States Government's Federal Trade Commission enacted legislation to curtail collection of information from children under the age of 13 (COPPA 1998). However, this legislation does not protect those aged 13 years or older, or the adolescent segment. This is surprising given that the adolescent segment is the most Internet-connected, and that privacy issues have generated so much attention. There have been no investigations that attempt to measure the degree to which this segment is aware and concerned about protecting their privacy. No studies researched the potential link between the consumer socialization process and behaviors and or attitudes, toward privacy concern.

Privacy concern is both a critically important and neglected consumer socialization outcome and parents, educators, and policy makers, can benefit from more research on this topic. For example, parents who understand the degree to which their children comprehend privacy issues can protect them from unwanted privacy intrusion. Alternatively educators and policy makers can develop and implement appropriate programs that educate and protect adolescents from unwanted or unknowing invasions of privacy.

In this paper we will answer two important questions:

- $\quad$ Are adolescents concerned about protecting their privacy when using the Internet?

- What consumer socialization components assist in the development of privacy concern amongst adolescents?

In Section 2 of this paper we discuss the consumer socialization framework and how it should be amended to include privacy concern. Section 3 describes and outlines the key elements of the adolescent privacy debate and highlights the factors that appear to enhance or hinder the development of privacy concern. In Section 4 we explain the relevant survey design and statistical procedures used in gathering and manipulating the data used in this study. Section 5 presents brief policy implications for marketers, parents, government, and educators.

\section{Section 2: Consumer Socialization: A Framework for Investigating the Issue of Privacy Concern}

The consumer socialization framework centres on the idea that adolescents learn to become consumers much like they learn other roles in society (e.g. student, friend, or sibling). The process of consumer socialization assumes that children and adolescents are not only products of their environment but are also influenced by external sources such as friends, the magazines they read, or the television shows they watch. Together, these influences shape the knowledge, attitudes, and skills acquired by the adolescent and are instrumental in their development as consumers. Consumer role attainment is an ongoing process with differing levels of knowledge, skill, and competency. For this reason, investigations into how individuals assume the consumer role differ in terms of their focus and span but share a common thread-the consumer socialization framework. Recall the consumer socialization framework includes four components. 
1. Social structural variables such as gender, age, socio-economic status, demographic factors, and any other variables that describe the social environment in which the child learns.

2. The socialising agents those who influence the learner by frequency of contact, primacy over the child, and/or control over the administration of rewards and punishments and include parents, peers, media, and schools.

3. The methods of learning such as 'modeling' (i.e. imitation), 'reinforcement' (i.e. rewards and punishments), or 'social interaction' (i.e. a combination of the two).

4. The learning outcomes refer to the set of knowledge, skills, and attitudes acquired through having experienced the socialization process. ${ }^{1}$

Together these four components describe the process by which children learn to become adults. Sociostructural variables are often used as control variables in consumer socialization and help researchers identify and distinguish between groups within the adolescent segment. For example, Moschis (1978) identifies a positive link between materialistic attitudes and adolescent males whilst Carlson and colleagues finds a link between parenting methods and socio-economic status (Carlson et al. 1990). Socialization agents are external sources which influence the adolescent by using tools such as modeling, reinforcement, or social interaction. Previous research has identified three primary socialization agents, parents, peers, and the media, as having the most influence on adolescent consumer learning (Churchill and Moschis 1979; Moore and Moschis 1983; Moore and Stephens 1975; Moschis et al. 1986; Moschis 1976; Moschis 1985; Moschis and Churchill 1978; Moschis and Mitchell 1986; Moschis and Moore 1978; Moschis and Moore 1979; Ward 1974). These studies have focused attention on the socialization agent and have omitted from their research the learning method used by the socialization agent. There are a number of reasons for this omission including the fact that socialization agents tend to vary their learning methods depending on time and particular context. We follow the lead of previous researchers and ignore the learning methods used by the socialization agent to transfer information to the adolescent. Instead we focus on the impact and influence of the socialization agent in affecting consumer socialization outcomes.

Consumer socialization is an ongoing process since cognitions and behaviors can change over time as the adolescent acquires more 'experience'. One would expect that a younger child with few experiences in the marketplace will have a lesser knowledge of consumer matters than an adolescent who may be given an allowance, hold a job, and has had many interactions in the marketplace. On this basis, we can hypothesise that knowledge of and concern for, privacy issues will depend upon having experienced the consumer socialization process. This implies that adolescents raised in homes where the Internet is used, discussed, and monitored should have a better awareness of privacy issues than those raised in homes where computer use is less frequently discussed or monitored. We will explore this hypothesis more thoroughly once we determine what are the key elements of the privacy debate.

\section{Section 3: Privacy}

In this section we define privacy and examine the history of privacy and privacy protection under the law. We then shift our attention to the issue of adolescent privacy concern.

\section{Privacy \& Privacy Protection Under U.S. Law}

Privacy was first described as the 'right to be let alone' by Warren and Brandeis. This first attempt at defining the concept in legal terms was done in the context of protecting one's personal information from being published in a public forum (Warren and Brandis 1890). Warren and Brandeis argued for inclusion of specific privacy protection under the law by pointing out that privacy is an inferred right ${ }^{2}$ and not a right explicitly

\footnotetext{
${ }^{1}$ This typology is commonly referred to in the literature. For a more detailed account of the theoretical foundations underlying these components see Moschis and Churchill (1978), Moschis and Moore (1978), Moschis (1985), and Roedder-John RoedderJohn, Deborah (1999), "Consumer Socialization of Children: A Retrospective Look at Twenty-Five Years of Research," Journal of Consumer Research, 26 (December), 183-213. who provides a more recent review.

${ }^{2}$ An inferred right is one that is 'assumed to exist' but is not explicitly written Warren, S. and L. Brandis (1890), "The Right To Privacy," Harvard Law Review, 4, 193..
} 
guaranteed by the constitution. According to Warren and Brandeis (1890) privacy protection under the law is fundamental to the freedom of the American people. Gaviston (1984) broadens Warren and Brandeis' (1890) focus on publication of personal information to include three key elements: anonymity, solitude, and secrecy. Anonymity is described as protection from undesired attention; solitude is a lack of physical proximity to others; and secrecy involves limiting the knowledge about an individual to others. From a consumer perspective, privacy is described by some as 'the ability to control the acquisition and use of personal information (Westin 1967). Others, like Goodwin (1991) believes consumer privacy is two-dimensional and involves control over the distribution of personal information and control over intrusion into ones environment via direct mail or telemarketing. Within this perspective Foxman \& Kilcoyne (1993) suggest consumer privacy is about who controls consumer data and whether the consumer is knowledgeable about its collection and how it will be used. Milne and Rohm (Milne and Rohm 2000) point out consumer privacy definitions include in one form or another the notion that privacy "centers on the consumers' ability to control personal information" (p. 239). They point out that an individual cannot control something that he/she has little, or no, knowledge about (Milne 2000). This explains why market researchers have sought to investigate the degree to which consumers are concerned ${ }^{3}$ with privacy issues and the extent to which they want to maintain control over the transfer of their personal details.

The appeal by Warren and Brandeis (1890) to grant citizens' the specific right to control their private information within the U.S. Constitution was not successful. As a result the ability to control one's personal information is not a specific constitutional right but is rather an inferred right, unless specifically addressed within the law. The constitution infers some general level of privacy protection in the $1^{\text {st }}, 4^{\text {th }}, 5^{\text {th }}, 9^{\text {th }}$, and $14^{\text {th }}$ amendments. However, only the $14^{\text {th }}$ amendment provides a basis for protecting a person's 'informational privacy' by protecting citizens from unwarranted wiretapping and other means of undercover surveillance (Spinello 1998).

Nonetheless, there are several laws enacted by Congress which protect specific privacy rights. For example the Fair Credit Reporting Act (1971) prevents credit reporting agencies from selling information to third parties but for "legitimate business purposes"- however, this is interpreted very broadly and credit reporting agencies are now the largest holders and sellers of private information. Alternatively, the Family Educational Rights and Privacy Act of 1974 allows parents and students access to school records and requires school administrators to inform parents when they provide student 'directory' information (name, address, phone number) to outside sources (Education 2001). Exemplifying the notion that privacy is not a right protected under the law unless specifically addressed is the U.S. Supreme Court ruling claiming that bank customers had no legal right of privacy for bank accounts held by financial institutions. As a result Congress enacted The Financial Privacy Act of 1978 to prevent financial institutions from disclosing bank account information to U.S. government agencies without informing the account holder first (Newsletters 2001). In a later effort to protect citizens' personal information held by government agencies congress enacted the Privacy Act of 1974 which allows individuals the right to both access and correct personal data held by any United States government federal agency (Justice 2002).

Historically, U.S. privacy protection laws have been enacted as a result of misuse or mishandling of data by various government or private agencies. Confronted with evidence that the Internet was prone to such data collection from children, the FTC passed the Children's Online Privacy Protection Act of 1998 (COPPA) ${ }^{4}$. Prior to the

\footnotetext{
${ }^{3}$ The use of the word 'privacy concern' is well documented as it relates to the measurement of privacy. See for example: Nowak, Glen J. and Joseph Phelps (1992), "Understanding Privacy Concerns," Journal of Direct Marketing, 6 (4 (Autumn)), 28-39.

, Sheehan, Kim Bartel (2002), "Toward a Typology of Internet Users and Online Privacy Concerns," Information Society, 18 (Jan-Feb), 21-32. , Sheehan, Kim Bartel and Mariea Grubbs Hoy (2000), "Dimensions of Privacy Concern Amongst Online Consumers," Journal of Public Policy and Marketing, 19 (Spring), 62-73.

, Sheehan, K.B. and M.G. Hoy (1999), "Flaming, Complaining, and Abstaining: How Online Consumers Respond to Privacy Concern," Journal of Advertising, 28 (3 Fall), 37-51.

, Sheehan, Kim Bartel and Mariea Grubbs Hoy (1998), "Privacy and On-Line Consumers: Comparisons with Traditional Consumer and Implications for Advertising Practice," in 1998 American Academy of Advertising Conference, Darrel D. Muehling (Ed.). Washington State University: Pullman.

, --- (1997), "Warning Signs on the Information Highway: An Assessment of Privacy Concerns of On-line Consumers," in Association for Education in Journalisim and Mass Communications Annual Conference. Chicago.

${ }^{4}$ A report titled "Web of Deception" published by the Center for Media Education Education, Center for Media (1996), "Web of Deception," Vol. 2002: Center for Media Education. was the first to document the collection of personal information from young children by Internet companies.
} 
Internet it was more difficult for companies to collect personal information from children and adolescents without consent from parents (Anthony and Cohn 2000). Previous data collection activities such as birthday clubs and subscriptions require parental involvement to facilitate membership (e.g. parent's must help fill out the form, assist in mailing, or permit subscription-based purchases). In such instances, the parent is in a position to mediate communication between the information gatherer and the child. By using the Internet, companies can communicate directly with children and parental mediation is not required to facilitate the flow of information. COPPA, alleviates this 'loophole' by requiring Web sites who direct products and services to children under the age of 13 to provide a privacy statement as well as obtain 'parental consent' when collecting personal information. COPPA protects children online by not only requiring parental consent but also provides a "Safe Harbor" list of Web sites for parents. Companies voluntarily apply for 'safe harbor' status by submitting an application to the FTC who verifies the site complies with all COPPA rules.

Critics of COPPA argue that the law leaves the remainder of the population unprotected from online invasion of privacy, particularly adolescents. Under the standards of COPPA, adolescents age 13 and older are regarded as 'adults', such that the responsibility of privacy protection falls to both the adolescent and/or the parent. Littman (2000) argues voluntary parental intervention is not enough as parents are inattentive to children's use of the Internet creating an environment in which children and teens can be easily exploited online. Heckman (1999) suggests that inattention to Internet use at home is not a result of 'poor parenting' but a function of the convergent nature of the technology. Heckman believes parents are at a disadvantage with the Internet technology as children often know more about the Internet than parents. Parents are therefore less knowledgeable about its uses and abuses. Moreover, because the Internet tends to be an individual, as opposed to a group experience, whereby parents do not interact or engage in communication whilst their children use the Internet (Heckman 1999). For example, co-viewing and co-consuming television and radio provides parents with some control over its use and the content of programs. Co-usage also permits 'debriefing' discussions once the programs are over.

Whilst the United States government has focused on protecting the privacy of children under age 13 online, a handful of other countries have taken broader measures to protect the privacy of citizens. In Europe, the Data Protection Directive gives citizens the right to know what data is being collected and what it will be used for as well as providing an 'opt out' option (Barker, 1996). The European Directive also bars the transfer of data to countries who do not have equally stringent privacy protection in place, and this may prevent countries from conducting business with one another in the global arena, including the United States where there is little privacy protection under the law.

\section{Adolescent Privacy Concern}

Prior to computerisation and more recently the Internet, personal information had no value beyond the current transaction. Today, however, personal information is bought and sold like a commodity (Spinello 1998). For example, three corporations that collect and sell credit history information, Trans Union, Equifax, and Experian, maintain files on more than $90 \%$ of adult Americans. In addition, there are more than 30,000 commercially available lists on various categories of North American purchasing behavior and more than 100,000 million consumers and businesses are profiled (Etzioni 2000).

Whilst there are few official marketing databases that collect information on children and teens there are countless databases that house information that are subsequently sold to 'third parties' (Mark 2001). Third party lists are derived from companies who collect information from consumers and subsequently sell the information to other companies. Sources for child related third party lists include restaurant birthday clubs, magazine subscriptions, catalog companies, product warranty registrations, and the Internet (Mark 2001). The Internet, however, provides a means by which companies can collect information from children and teens with little or no intervention from parents. Therefore the Internet facilitates an environment in which parental mediation of information flow is reduced. Whilst COPPA protects those under the age of 13 by requiring parental consent before data can be collected, adolescents are not protected under the law. Consequently, privacy protection for the adolescent segment

The report brought online privacy invasion to the forefront of public attention and resulted in a FTC investigation into the collection of information on the Internet ultimately leading to the COPPA legislation. 
is dependent upon the teen and/or parent's knowledge of online privacy issues and the purposeful engagement of behavior that assists in protecting personal information whilst online. In lieu of engaging in purposeful behaviors that protect privacy online, adolescents must depend on industry self regulation. Ethical marketers are likely to voluntarily 'self regulate' by following policies and guidelines suggested by industry. For example members of the Direct Marketing Association (DMA) are encouraged to post online privacy policies and the DMA specifically recommends that marketers who market to children post notices to obtain parental permission before collecting information online. Likewise the American Marketing Association has embraced a Code of Ethics for Marketing on the Internet and asks marketers to "avoid harm by protecting the rights of privacy, ownership and access" (AMA 2002). Although responsible marketers will likely follow industry guidelines for protecting the privacy of consumers, unscrupulous companies are unlikely to do so thereby creating the opportunity for exploitation of vulnerable consumers.

\section{Consumer Socialization Process \& Privacy Concern}

Whilst the government has protected the privacy of Internet users under the age of 13 years old through COPPA, it provides no protection for the adolescent segment, a segment that not only purports to have wide use of the Internet, but also are heavy Internet users. Surprisingly, there has been no previous research that has investigated the degree to which those 13 and older are concerned about privacy issues. Recall under the terms of the law, adolescents ages 13 yrs and older are perceived as being in equal standing with adults as to the protection of their private information when using the Internet. For this reason, it is important to have an insight into what adolescents understand about privacy matters. Moreover, it is also relevant to determine links between the consumer socialization process and the development of privacy concern in adolescents. This information will assist policy makers, educators, parents, and marketers in identifying those adolescents who are not aware of privacy issues, as well as to aid them in developing programs and resources that foster the development of privacy concern in adolescents. We are now concerned with understanding what specific socio-structural variables, socialization agents, and consumer socialization outcomes affect the development and acquisition of privacy concern in adolescents.

We can 'locate' privacy concern in the final component of the consumer socialization frameworkconsumer socialization outcomes. Privacy concern can be classified as a specific knowledge or cognition associated with consumer learning. Previous researchers consistently refer to privacy concern within the context of consumer learning, competency, or knowledge (Culnan 1995; Nowak and Phelps 1992; Sheehan 2002; Sheehan and Hoy 2000; Sheehan and Hoy 1999; Sheehan and Hoy 1998; Sheehan and Hoy 1997). This implies that the development and presence of privacy concern is dependent upon socio-structural variables and socialization agents and is likely to be correlated with other socialization outcomes.

\section{Socio-Structural Variables}

Socio-structural variables, including age, gender and socio-economic background, have been linked to privacy concern issues in previous research although not from a consumer socialization, or non-adult perspective. For example researchers have found statistically significant correlations between concern for ones privacy and the adoption of behaviors that protect one's privacy (Sheehan and Hoy 1999). One of these privacy protecting behaviors, requesting name removal from direct mailing lists, has been linked to consumers who tend to be less educated and non-white (Culnan 1995). With regard to this finding, Culnan (1995) argues, "...the implied social contract between direct marketers and these consumers may be more likely to be unfair" (p.17). Alternatively Nowak and Phelps (1992) find older adults tend to be more concerned with privacy issues than younger adults and those with higher education levels (4+ yrs of college) tend to request name removal from direct marketing lists more often than those with only 'some' college or technical school education. A study conducted by Equifax lends additional insight into the importance of age on privacy concern; Equifax finds adults under age 30 are more enthusiastic about the use of consumer-based information services and are more willing than other age groups to engage in tradeoffs involving personal information (Associates 1991). 
We can assume that privacy concern will be affected by the same socio-structural variables as other consumer socialization outcomes namely, age, gender, and socio-economic status. Conventional wisdom suggests that privacy concern will be positively correlated with older, female adolescents from higher socio-economic status households. It is reasonable to assume that the communicative parenting approach is more likely used with females than with males. This increased level of communication and discussion between parents and teen suggests more opportunities for discussing consumer-related matters. Lastly, conventional wisdom suggests that compared with younger adolescents, older adolescents have increased levels of pocket money and more experience in the marketplace.

\section{The Socialization Agents' influence on Privacy Concern}

No research has been conducted about 'privacy concern' with the adolescent market and little is known about how socialization agents might affect the acquisition and development of privacy concern amongst this segment. Previous consumer socialization research points to three primary socialization agents that influence consumer learning - parents, peers, and the media (Moschis 1976; Moschis and Churchill 1978). It is reasonable to expect that these same socialization agents will have some influence, positive or negative, on the development of privacy concern in adolescents.

Few have produced research with the specific intent of linking parenting methods to consumer socialization outcomes, although there is some research that suggests such links exist. For example, Mangleburg and Bristol (1998) link concept-oriented family communication (COFC) to scepticism to advertising and marketplace knowledge whilst Moschis (1979) finds a negative link between socio-oriented family communication (SOFC) and marketplace knowledge. (Recall COFC parents allow children to form their own opinions based on life experience whilst SOFC parents stress family harmony brought about by deference to authority.)

The second socialization agent said to influence the consumer socialization process is peer influence (Moschis and Churchill 1978). In early research peer influence was determined in terms of frequency of interaction with peers. More recently investigators have used a more sophisticated measurement instrument that takes into account the different types of peer influence that might exist. Susceptibility to peer influence was derived from that research and describes a general personality trait that varies by individual. It is two dimensional in that it captures the degree to which one will conform to the expectations of others (normative peer influence) and the degree to which one will rely on others' as evidence about reality (informative peer influence) (Bearden et al. 1989; Bearden and Netermeyer 1999). General peer influence has been investigated in terms of consumer decision making (Childers and Rao 1992), purchase influence (Bachmann et al. 1993; Moschis and Mitchell 1986), and consumer learning (Churchill and Moschis 1979) although only recently have researchers measured the peer influence in terms of normative and informative peer influence. Mangleburg and Bristol (1998) link normative peer influence to the development of scepticism of advertising whilst Moschis (1985) suggests parents who stress socio-oriented communication (protective) may contribute to teens' susceptibility to peer group influence. In this research, we use peer influence in both normative and informative terms in order to determine if one or the other is more strongly related to the development of privacy concern in teens.

The last socialization agent, media, refers to the impact of television and Internet use on the development of privacy concern. Whilst the effects of the Internet as a socialization agent have not been investigated previously, numerous studies have explored the impact of television viewing on consumer socialization. Although none of these studies specifically deal with the issue of privacy concern, they add further evidence to support the claim that socialization agents influence the consumer socialization process including the development of various consumer socialization outcomes. For example, Churchill and Moschis (1979) find a relationship between television viewing and family communication about consumption as well as the development of materialistic attitudes. In the same study, they find a negative link between increased levels of television viewing and peer communication about consumption suggesting that whilst increased television viewing appears to generate discussion with parents it does not do so with peers. This finding is of interest to us and may suggest a similar link between Internet use and ensuing family discussions. Ward and Wackman (1971) find adolescents are likely to discuss products they have seen on television with parents. Moore and Stephens (1975), however, suggest that adolescents may pay attention to 
television commercials and discuss them with their peers. Additionally, Reisman and Roseborough (Riesman and Roseborough 1955) suggest that television viewing directly affects adolescents' motivation for 'expressive' consumption. In other words, adolescents learn the 'right' things to buy which assists them in gaining acceptance by the peer reference group. Researchers have also sought to link television viewing to specific consumer skills. For example, Moshis and Moore (1978) note a link between brand knowledge and increased television viewing. More recently, Mangleburg and Bristol (1998) find a positive relationship between the development of scepticism to advertising and increased levels of television viewing.

Whilst no research has been conducted to specifically link privacy research with television viewing, a recent study finds newspaper reading is negatively correlated with concern for privacy issues (Nowak and Phelps 1992). In other words, adult consumers who regularly read a daily newspaper have less concern about privacy issues than those who do not read the daily newspaper regularly. Nowak and Phelps (1992) also find a statistically significant link between hearing about the use or misuse of personal information and increased levels of privacy concern, suggesting that the 'human' influence may be stronger than the media influences in the development of privacy concern. More research is warranted to determine what influences may or may not affect the acquisition of privacy concern. This information would help appropriate entities understand what resources and tools to use to communicate the importance of privacy issues to adolescent Internet users.

There is also a gap in the research with regards to the effects of Internet use on the development of adolescent privacy concern. Some studies, including findings in this research, imply a plausible link between the presence of privacy concern and Internet.

More concretely, our findings have shown a negative link between independent use of the Internet and consumer socialization outcomes. We also show that those adolescents who use the Internet independent of other media appear to develop less scepticism to advertising than those who use the Internet and television simultaneously and that those who use both media simultaneously appear to develop more scepticism than those who watch only television and do not use the Internet. These relationships suggest that there may well be similar links between Internet use and/or television use and the development of privacy concern.

Conventional wisdom suggests there are links between parenting methods and monitoring and co-viewing of the Internet. Our data show parents who practice both socio-oriented and concept-oriented family communication (consensual) appear to monitor and control Internet use more than other parents and adolescents from these homes rate higher on the privacy concern scale. These findings shed light on the consumer learning implications of Internet use by adolescents by suggesting co-Internet use by the parents and adolescent may be correlated with a higher level of privacy concern.

\section{Consumer Socialization Outcomes and Privacy Concern}

Previous research with the adult population also suggests there may be links between privacy concern and other consumer socialization outcomes. Recall consumer socialization outcomes are knowledge, skills, behaviors, and cognitions that are learned as a result of having gone through the consumer socialization process. Previous research in consumer socialization has linked outcomes together. For example, Mangleburg and Bristol find a link between the increased levels of scepticism to advertising and marketplace knowledge. Their finding is consistent with conventional wisdom suggesting that the more knowledgeable one is of the marketplace the more one will know about specific consumer matters. Nowak and Phelps' (1992) study links hearing about use or misuse of private information with increased levels of privacy concern and this can also be interpreted as an indication that simple knowledge of the occurrence increases concern for privacy. There is, however, no other research that supports or refutes these hypotheses. More research is needed to determine if consumer socialization outcomes affect one another in more explicit ways.

\section{Section 4: Methodology, Variables, and Results}

To access the degree to which privacy concern is associated with the consumer socialization process we rely on data administered a traditional pen and paper survey over a two-day period of time to all students located in a 
midwestern high school. The survey was completed over a five-month period of time in 2000 and underwent both pre-testing exercises and institutional review. Respondents were informed of the purpose of the survey and were given the opportunity to win one of 25 fifteen-dollar gift certificates for completing the questionnaire. Unbeknownst to students a $\$ 1,200$ charitable donation was provided to the school to encourage participation. Nine hundred and sixty-six completed surveys were received, and after screening for missing and incomplete data, 713 were deemed appropriate for statistical analysis. The four main age groups (14-15 yrs), (15-16 yrs), (16-17 yrs), (17-18 yrs) are evenly represented with associated percentage figures of $20.5 \%, 25.3 \%, 23 \%$, and $18 \%$. Few are aged 13 and 19 ( $2 \%$ and $0.4 \%$ ) as entry age for the first year of high school is 14 and 17 for entry to the final year. There is a slightly higher female contingent (56\% as opposed to a national figure of 52\%) but to the best of our knowledge this discrepancy is spurious and has not affected our results in any way. The ethnic background of respondents was $75 \%$ White, $4 \%$ Black, 3\% Hispanic, 4\% Asian, 3\% Native American and 11\% gave no response.

The focus of this study is to assess adolescent privacy concern and how teen's learn to protect themselves whilst online. Recall that to determine the degree to which adolescents are concerned with privacy issues we rely on previous empirical studies that explore consumer privacy concern. Schultz (1990) suggests there are few studies that attempt to examine the underpinnings of consumer privacy concern. In an effort to shed light on this underdeveloped area of research Katz and Tassone (1990) attempt to characterise the degree to which American's are concerned with privacy issues by reviewing results of public opinion surveys from 1978-1989. Their findings indicate that privacy concern amongst Americans increased from 30 percent to 45 percent over an eleven-year period of time. Nowak and Phelps (1992) follow with a study designed to specifically explore why consumers are concerned about privacy issues and what they are concerned about. For example they find adult consumers were most concerned about the availability of personal financial data as well as video rental information whilst they were least concerned about the availability of information on consumption or media habits. Moreover they find most respondents indicated Americans have less privacy today than 10 years ago and nearly all supported government intervention to protect their privacy.

Our approach to the measurement of privacy concern most closely aligns with that of Sheehan and Hoy (1999) who capture privacy concern by tapping respondents' concern with specific privacy issues. Our study differs from that of Sheehan and Hoy (1999) in that our survey was a self-administered questionnaire taken by adolescents age 13-19 as opposed to an email survey sent to adult consumers. Moreover we deleted one item included in Sheehan and Hoy's (1999) measure as the item was identified in focus group pre-testing as 'not understandable'. Respondents indicated they did not understand what a 'newsgroup' was for the item, "You are asked to provide names of newsgroups read to access a home page." The result is a 14-item index.

Because no Internet privacy research has been conducted for the adolescent segment we have no basis from which to access the degree to which the value of the mean score reflected by our sample is 'high' or 'low' privacy concern. For exploratory purposes we use the scoring scale devised by Sheehan and Hoy (1999) as a 'benchmark' for comparison. In order to facilitate this comparison we recode the 14 items using a 6 point 1-7 scale where $1=$ not concerned and $7=$ extremely concerned.

The mean privacy concern score was 32.21 (without adding in an additional score) with possible scores ranging from 1-98. Sheehan and Hoy (1999) report a mean score of 58.86 suggesting privacy concern amongst adults is higher than that of adolescents. One would expect adults to score higher on privacy concern as a result of increased experience in, and knowledge of, the marketplace.

In this study we use simple correlation coefficients to test the association between privacy concern (our dependent variable) and components of the consumer socialization process including parenting communication methods, peer influence, and the influence of television and the Internet (Table 1-1).

Correlations that are significant at the $p<.05$ are highlighted in grey. In order to further access the impact of the socialization process on privacy concern we perform correlations between the independent variables and the consumer socialization process (Table 1-2). 
TABLE 1-1: Privacy Concern and the Consumer

Socialization Process

\begin{tabular}{|c|c|c|}
\hline \multirow{4}{*}{ 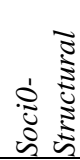 } & AGE & .04 \\
\hline & GENDER & $.09 *$ \\
\hline & SES & .05 \\
\hline & HHSIZE & .02 \\
\hline \multirow{12}{*}{ 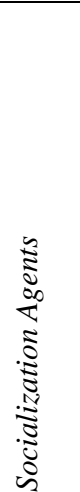 } & LF & 2.04 \\
\hline & PL & .07 \\
\hline & PR & $.29 *$ \\
\hline & $\mathrm{CON}$ & $.24 *$ \\
\hline & NPI & $.11 *$ \\
\hline & IPI & $.15^{*}$ \\
\hline & COVIEWINT & $.10 *$ \\
\hline & CHECKINT & $.06 * *$ \\
\hline & INTERNET & $.09 *$ \\
\hline & COVIEWTV & $.08 *$ \\
\hline & CHECKTV & $.14 *$ \\
\hline & TV & .04 \\
\hline \multirow{2}{*}{ 葋 } & SKEP & $.07 * *$ \\
\hline & MKTKNOW & $.13 *$ \\
\hline
\end{tabular}

*statistical significance at $\mathrm{p}<.05$

**approaching significance at $\mathrm{p}<.10$

Table 1-2: The Relationship between Variables Significantly Linked to Privacy Concern and the Consumer Socialization Process

\begin{tabular}{|c|c|c|c|c|c|c|c|c|c|c|}
\hline \multicolumn{2}{|c|}{ Dependent Variable } & PR & $\mathrm{CON}$ & IPI & $\begin{array}{c}\text { CHECK- } \\
\text { TV }\end{array}$ & $\begin{array}{c}\text { MP } \\
\text { KNOW }\end{array}$ & NPI & $\begin{array}{c}\text { CO VIEW } \\
\text { INT }\end{array}$ & $\begin{array}{c}\text { INTER- } \\
\text { NET }\end{array}$ & $\begin{array}{l}\text { GEN- } \\
\text { DER }\end{array}$ \\
\hline \multicolumn{2}{|c|}{$\begin{array}{l}\text { Correlation between the } \\
\text { dependent variable and } \\
\text { privacy concern }\end{array}$} & $(.29)$ & $(.24)$ & $(.15)$ & $(.14)$ & $(.13)$ & $(.11)$ & $(.10)$ & $(.09)$ & $(.09)$ \\
\hline \multirow{4}{*}{ 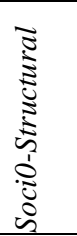 } & AGE & -011 & $-.15^{*}$ & $\begin{array}{c}.07 * \\
*\end{array}$ & $.20 *$ & .06 & $-.10 *$ & $-.07 * *$ & -.07 & -.02 \\
\hline & GENDER & -.08 & -.08 & $.17 *$ & .04 & -.06 & $.10^{*}$ & $-.07 * *$ & $-.18 *$ & \\
\hline & SES & .03 & .03 & -.01 & $.09 * *$ & $.11 *$ & -.03 & .05 & .08 & -.07 \\
\hline & HHSIZE & .06 & -.04 & $\begin{array}{c}.07 * \\
*\end{array}$ & $.10^{*}$ & .03 & .03 & $.11 *$ & -.01 & -.01 \\
\hline \multirow{12}{*}{ 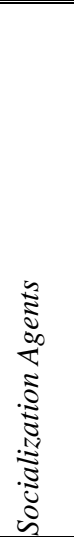 } & LF & & & .30 & $.14 * *$ & .12 & $.16^{*}$ & $.13 * *$ & .04 & $.14 * *$ \\
\hline & PL & & & .09 & .11 & .03 & -.09 & .11 & -.04 & .10 \\
\hline & PR & & & $.25^{*}$ & $.15^{*}$ & .01 & $.13 * *$ & .02 & .12 & .06 \\
\hline & $\mathrm{CON}$ & & & $.14 *$ & $.29 *$ & $.15 *$ & $.12 * *$ & $.21 *$ & -.06 & -.08 \\
\hline & NPI & .13 & .12 & $\begin{array}{c}.50 * \\
*\end{array}$ & $.13^{*}$ & -.02 & & $.13^{*}$ & .03 & $-.10 *$ \\
\hline & IPI & $.26^{*}$ & $.14 *$ & & $.11 *$ & $.16^{*}$ & $.50 * *$ & $.10^{*}$ & $.13 *$ & $.17 *$ \\
\hline & COVIEWINT & .02 & $.21 *$ & $.10 *$ & $.28 *$ & -.01 & $.13 *$ & & $.13 *$ & $-.07 * *$ \\
\hline & CHECKINT & $.21 *$ & $.20 *$ & .03 & $.38 *$ & -.03 & $.11 *$ & $.35^{*}$ & .05 & $-.08 *$ \\
\hline & INTERNET & .12 & -.06 & -.04 & $-.06 * *$ & & .03 & $.13^{*}$ & & \\
\hline & COVIEWTV & .05 & $.12 * *$ & .14 & $.28 *$ & $.08 *$ & $.07 *$ & $.21 *$ & $-.08 *$ & $.09 *$ \\
\hline & CHECKTV & $.15 *$ & $.29 *$ & $.11 *$ & & .02 & $.13 *$ & & $-.06 * *$ & .04 \\
\hline & TV & .03 & .07 & -.02 & .01 & -.03 & $.15^{*}$ & -.01 & $.19 *$ & $-.22 *$ \\
\hline \multirow{2}{*}{$\stackrel{\Xi}{\Xi} \approx$} & SKEP & .07 & .06 & $.30 *$ & .01 & $.21 *$ & $.36^{*}$ & .06 & -.03 & .01 \\
\hline & MKTKNOW & $.22 *$ & $.21 *$ & $.42 *$ & .02 & $.21 *$ & -.02 & -.01 & .01 & -.06 \\
\hline
\end{tabular}




\section{Section 5: Conclusion}

Whilst the issue of privacy has been discussed and debated for over 100 years it has only recently become the focus of public attention. Proliferation of the Internet technology into American homes has been the catalyst for the collection of data from consumers as they 'surf' the Internet from the privacy of home. However, many Internet users do not have a thorough understanding or knowledge of the data collection activities that exist whilst online. Sheehan and Hoy (1999) suggest that without awareness of privacy issues, it is impossible for Internet users to protect their privacy online. In other words, in order for adolescents to protect their privacy online, they must have some degree of privacy concern.

In this study we i) accessed the level of adolescent privacy concern and, ii) subsequently advance the discussion to link privacy concern and the consumer socialization process - to determine what socialization processes might influence its development. By doing so, we not only explore the current state of adolescent privacy concern but provide insight into influences and socialization components that may be related to the development of privacy concern in adolescents. This task is accomplished through data derived from a traditional pen/paper survey administered to 1176 high school students ages 13-19 in a mid-western community in the United States of America.

Overall, the privacy concern score indicated by the adolescents in this study appears to be much lower than those found by Sheehan and Hoy (1999). Some of the variance between the scores may be a result of the differing survey methods and samples. For example, Sheehan and Hoy's (1999) score may reflect sample bias as they survey adults via email who may have more experience with the Internet and are therefore more aware of privacy issues. Nevertheless, our findings suggest that adolescents do not appear to be concerned with issues of privacy or privacy invasion. Nowak and Phelps (1992) suggest that "...knowledge, or lack thereof, is a major determinant of privacy concern" ( $\mathrm{p}$ 37). They also point out that in order to protect one's privacy online, consumers must have a knowledge of the various means by which privacy is violated or invaded, in the online environment. In other words, in order for adolescents to protect their privacy online, they must be able to identify ways in which personal privacy can be relinquished, both knowingly and unknowingly, on the Internet. In order for the appropriate entities to develop programs and resources that educate adolescents on how their privacy may be invaded, or relinquished, more information is needed to determine what vehicles might convey the information at the right time and in the right format.

The second objective of this study is to access the possible links between privacy concern and the consumer socialization process in order to shed light on the consumer socialization components that may be associated with privacy concern. The data suggest links do exist between adolescent privacy concern and the consumer socialization process. For example we find females appear to be associated with privacy concern more than males. The data also show, as expected, that both protective and consensual parenting are associated with privacy concern. We find socio-oriented parenting is not without benefits. We also observe statistically significant correlations between privacy concern and parental monitoring and control of Internet and television use. Of particular interest is the relationship between co-viewing the Internet (COVIEWINT) and privacy concern $(.10 ; \mathrm{p}<.05)$ versus checking Internet use (CHECKINT) and privacy concern $(.06 ; \mathrm{p}<.10)$. Whilst we make a cautious comparison given the significance of (CHECKINT) it appears co-viewing the Internet with teens may be a better approach to the development of privacy concern than simply checking which web sites are being visited. This finding supports finding by Novak and Phelps (1992) who suggest that hearing about privacy issues results in higher privacy concern. Those parents who co-view the Internet with adolescents are likely to engage in conversations with their adolescents, which result in more knowledge about appropriate online behaviors.

In addition to the link between parenting and privacy concern, the data show a positive statistically significant relationship between informative peer influence and privacy concern. These findings imply that privacy concern is not only associated with socio-oriented parenting methods, but peers are also likely to influence its development. Recall informative peer influence is more 'overt' than normative peer influence and describes adolescents' inclination to solicit advice and ask questions about products or purchases. We also note informative peer influence is correlated $(\mathrm{p}<.05)$ with all of the dependent variables that are associated with privacy concern (Table 6). More concretely, the data suggest that informative peer influence is associated with privacy concern and 
is in turn associated with all of the variables that are associated with privacy concern. More research is warranted, conceivably in the form of path analysis, to determine the extent to which the parental and peer influence are related to the development of privacy concern.

Policy makers, marketers, and educators have a social responsibility to not only protect and prevent the exploitation of vulnerable consumers but to educate them on how to protect their personal information in the online environment. Policy makers must enact laws that prevent companies from 'taking' information from consumers without their knowledge or consent. On the other hand, the marketing community must continue to 'self-regulate' and participate in the ethical collection, use, and dissemination of personal information particularly when dealing with young consumers. Educators, particularly teachers and school systems, have a responsibility to both inform and protect young consumers with regard to privacy issues. Schools systems should take the lead in this endeavour as adolescents are exposed to, and use, the Internet in nearly all schools in the United States. Moreover, American schools systems have increasingly become the catalyst for marketing activities in exchange for free school equipment (e.g. TVs, VCRs, computers) and programs.

The results of this study demonstrate the need for more research on the development of adolescent privacy concern. Specifically more research is needed to determine the degree to which adolescents understand privacy issues relative to adults. If a discrepancy exists, as results suggests, then adolescents should perhaps be protected by the law and treated as 'children' as opposed to 'adults'. This information is vitally important to policy makers who through the COPPA law have sought to protect only children ages 13 or younger, thereby leaving those 13 and older the responsibility of safeguarding their own personal privacy. More research is also needed to determine what behaviors teens' currently engage in to protect their privacy. Finally, more research is needed to shed light on the consumer socialization process as a whole and its influence on the development of privacy concern in adolescents.

\section{References}

1. $\quad$ AMA (2002), "American Marketing Association: Code of Ethics for Marketing on the Internet," Vol. 2002: American Marketing Association.

2. Anthony, Barbara and Thomas Cohn (2000), "Putting Parents Back in Charge of Kids' Privacy," Computerworld, 34 (20 (May 15)), 36.

3. Associates, Louis Harris and (1991), Harris-Equifax Consumer Privacy Survey 1991. Atlanta, GA: Equifax Inc.

4. Bachmann, Gwen Rae, Deborah Roedder John, and Akshay R. Rao (1993), "Children's Susceptibility to Peer Group Purchase Influence: An Explanatory Investigation," Advances in Consumer Research, 20, 46368.

5. Bearden, William O and Richard G Netermeyer (1999), Handbook of Marketing Scales (Second ed.). Thousand Oaks, California: Sage Publications.

6. Bearden, William O., Richard G. Netemeyer, and Jesse E. Teel (1989), "Measurement of Consumer Susceptibility to Interpersonal Influence," Journal of Consumer Research, 15 (March), 473-81.

7. Carlson, Les, Sanford Grossbart, and Ann Walsh (1990), "Mother's Communication Orientation and Consumer-Socialization Tendencies," Journal of Advertising, 19 (Number 3), 27-38.

8. Childers, Terry L. and Akshay R. Rao (1992), "The Influence of Famial and Peer-based Reference Groups on Consumer Decisions," Journal of Consumer Research, 19 (September), 198-211.

9. Churchill, Gilbert A. and George P. Moschis (1979), "Television and Interpersonal Influences on Adolescent Consumer Learning," Journal of Consumer Research, 6 (June 1979), 23-35.

10. Colkin, Eileen (2001), "Kids These Days," Informationweek, 824 (February), RB1-RB8.

11. COPPA (1998), "Children's Online Privacy Protection Act of 1998," U.S.C.

12. Culnan, Mary J. (1995), "Consumer Awareness of Name Removal Procedure: Implications for Direct Marketing," Journal of Direct Marketing, 9 (2), 10-19.

13. Education, Center for Media (1996), Web of Deception, Vol. 2002: Center for Media Education.

14. Education, Department of (2001), "Family Educational Rights \& Privacy Act (FERPA)," Vol. 2002: Department of Education.

15. Etzioni, Amitai (2000), "The New Enemy of Privacy: Big Bucks," Challenge, 43 (3 (May/June)), 91-106. 
16. Foxman, Ellen and Paula Kilcoyne (1993), "Information Tehcnbology, Marketing Practice and Consumer Privacy: Ethical Issue," Journal of Public Policy and Marketing, 12 (Spring), 106-19.

17. Gray, Christopher (1999), "America Circa 1999," Vol. 2001: The Austin Chronicle.

18. Heckman, James (1999), "Today's Game is Keep Away," Marketing News, 33 (14), 1, 7.

19. Justice, United States Department of (2002), "The Privacy Act of 1974," Vol. 2002: United States Department of Justice.

20. Katz, James and A. Tassone (1990), "The Poll: Public Opinion Trends-Privacy and Information Technology," Public Opinion Quarterly, 54, 125-43.

21. Kehoe, Colleen, James Pitkow, and Kimberly Morton (1997), Eighth WWW User Survey, Vol. 2002: Georgia Institute of Technology.

22. Littman, Margaret (2000), "How Marketers Track Underage Consumers," Marketing News, 34 (10 (May 8)), 4,7 .

23. Mangleburg, Tamara F. and Terry Bristol (1998), "Socialization and Adolescents' Skepticism Toward Advertising," Journal of Advertising, 27n3 (Fall), 11-21.

24. Mark, Amanda (2001), "Keen on those Elusive 'Tweens'," Catalog Age, 18 (2 (Feb)), 31.

25. Milne, George (2000), "Privacy and Ethical Issues in Database/Interactive Marketing \& Public Policy: A Research Framework and Overview of the Special Issue," Journal of Public Policy and Marketing, 19 (Spring), 1-6.

26. Milne, George and Andrew J. Rohm (2000), "Consumer Privacy and Name Removal Across Direct Marketing Channels: Exploring Opt-In and Opt-Out Alternatives," Journal of Public Policy and Marketing, 19 (2 (Fall)), 238-49.

27. Montgomery, Katherine and Shelley Pasnik (1996), Web of Deception: Threats to Children from Online Marketing, Vol. 2002: Center for Media Education.

28. Moore, Roy L. and George P. Moschis (1983), "Role of Mass Media and the Family In Development of Consumption Norms," Journalism Quarterly, 60 (Spring), 67-73.

29. Moore, Roy L. and Lowndes F. Stephens (1975), "Some Communication and Demographic Determinants of Adolescent Consumer Learning," Journal of Consumer Research, 2 (September), 80-92.

30. Moschis, George P (1985), "The Role of Family Communication in Consumer Socialization of Children and Adolescents," Journal of Consumer Research, 11 (March), 898-913.

31. Moschis, George P. and Gilbert A. Churchill (1978), "Consumer Socialization: A Theoretical and Empirical Analysis," Journal of Marketing Research (November), 599-609.

32. Moschis, George P. and Linda G. Mitchell (1986), "Television Advertising and Interpersonal Influences on Teenagers' Participation in Family Decisions," in Advances in Consumer Research Vol. 13. Urbana, IL: Association for Consumer Research.

33. Moschis, George P. and Roy L. Moore (1978), "An Analysis of the Acquisition of Some Consumer Competencies Among Adolescents," Journal of Consumer Affairs, 12 (2 Winter), 277-91.

34. --- (1979), "Decision Making Among the Young: A Socialization Perspective," Journal of Consumer Research, 6 (September), 101-12.

35. Moschis, George Parthenios (1976), "Acquisition of the Consumer Role by Adolescents," Doctor of Philosophy, University of Wisconsin.

36. Moschis, George, Andajali E. Prahasto, and Linda G. Mitchell (1986), "Family Communication Influences

37. Newsletters, Access Reports (2001), "Right to Financial Privacy Act," Vol. 2002: Access Reports Newsletters.

38. Nowak, Glen J. and Joseph Phelps (1992), "Understanding Privacy Concerns," Journal of Direct Marketing, 6 (4 (Autumn)), 28-39.

39. Riesman and Roseborough (1955), "Careers and Consumer Behavior," in Consumer Behavior, Vol II: the Life Cycle and Consumer Behavior, Lincoln H. Clark, Ed. New York: New York University Press.

40. Roedder-John, Deborah (1999), "Consumer Socialization of Children: A Retrospective Look at TwentyFive Years of Research," Journal of Consumer Research, 26 (December), 183-213.

41. Schultz, Don E. (1990), "Plowing New Research Ground with New Plowshares," Journal of Direct Marketing, 4 (3), 4-6.

42. Sheehan, K.B. and M.G. Hoy (1999), "Flaming, Complaining, and Abstaining: How Online Consumers Respond to Privacy Concern," Journal of Advertising, 28 (3 Fall), 37-51. 
43. Sheehan, Kim Bartel (2002), "Toward a Typology of Internet Users and Online Privacy Concerns," Information Society, 18 (Jan-Feb), 21-32.

44. Sheehan, Kim Bartel and Mariea Grubbs Hoy (2000), "Dimensions of Privacy Concern Amongst Online Consumers," Journal of Public Policy and Marketing, 19 (Spring), 62-73.

45. ---- (1998), "Privacy and On-Line Consumers: Comparisons with Traditional Consumer and Implications for Advertising Practice," in 1998 American Academy of Advertising Conference, Darrel D. Muehling (Ed.). Washington State University: Pullman.

46. --- (1997), "Warning Signs on the Information Highway: An Assessment of Privacy Concerns of On-line Consumers," in Association for Education in Journalisim and Mass Communications Annual Conference. Chicago.

47. Spinello, Richard (1998), "Privacy Rights in the Information Economy," Business Ethics Quarterly, 8 (4 (Oct)), 723-42.

48. Ward, Scott (1974), "Consumer Socialization," Journal of Consumer Research, 1 (September), 1-17.

49. Ward, Scott and Daniel Wackman (1971), "Family and Media Influences on Adolescent Consumer Learning," American Behavioral Scientist, 14 (January/February 1971), 415-27.

50. Warren, S. and L. Brandis (1890), "The Right To Privacy," Harvard Law Review, 4, 193.

51. Westin, Alan (1967), Privacy and Freedom. New York: Atheneum.

\section{Notes}

